\title{
APTIDÃO FÍSICA DE POLICIAIS MILITARES DO 16 BATALHÃO DO ESTADO DO PARANÁ
}

\section{ARTIGO ORIGINAL}

BONATO, José Douglas ${ }^{1}$

ALMEIDA, Pablo De ${ }^{2}$

BONATO, José Douglas. ALMEIDA, Pablo De. Aptidão física de policiais militares do 16ํㅡㄹatalhão do Estado do Paraná. Revista Científica Multidisciplinar Núcleo do Conhecimento. Ano 05, Ed. 06, Vol. 10, pp. 116-128. Junho de 2020. ISSN: 24480959, Link de acesso: https://www.nucleodoconhecimento.com.br/educacaofisica/policiais-militares

\section{RESUMO}

Profissionais militares buscam, de maneira contínua, o aperfeiçoamento de suas performances, de modo a atender melhor às necessidades da sociedade. A realização das atividades que os profissionais exercem demanda requisitos que viabilizam a execução eficiente das atividades relacionadas à essa profissão. Destarte, policiais militares devem, em sua rotina, preparar-se fisicamente para que o desempenho de suas tarefas seja eficaz, havendo, portanto, responsabilidade perante as situações que the são apresentadas. Para se avaliar o condicionamento físico dos profissionais militares do contexto paranaense, é aplicado o Teste de Aptidão Física (TAF), em que

1 Bacharel em Educação Física; Pós Graduado em Treinamento Esportivo e Personalizado; Pós Graduado em Segurança Pública.

2 Doutorado em andamento em Ciências Farmacêuticas. Doutorado em andamento em Ciencias De La Educación. Mestrado em Educação Física. Especialização em MBA em Gestão do Conhecimento na Educação Superior. Especialização em Fisiologia do Exercício e do Desporto. Graduação em andamento em Fisioterapia. Graduação em Educação Física. 
vários testes são aplicados aos profissionais militares, dentro e fora dos batalhões, objetivando verificar os índices de aptidão física dos militares, mostrando se estão aptos ou não para o trabalho. Portanto, o objetivo desta pesquisa foi revisar alguns aspectos voltados à esse condicionamento a partir do TAF, e, para tanto, a amostra contemplou 23 policiais do $16^{\circ}$ Batalhão da Polícia Militar (BPM), todos do sexo masculino, com idade entre 29 e 52 anos e que possuem no mínimo 10 anos de serviço operacional. Os policiais foram submetidos aos testes de flexão na barra fixa, flexão de braço, Teste de Cooper e Shuttle Run. A média de idade da população avaliada foi de 40,56 anos. Os policiais obtiveram média de 11 flexões na barra to tipo fixa, 28,5 flexões com o braço, 2,368m de distância percorrida no Teste de Cooper e 10,48 segundos para realizar o Shuttle Run. Concluiu-se que os policiais avaliados apresentaram níveis desejáveis de força e condicionamento aeróbio, uma vez que as médias apontam que houve a superação do mínimo exigido em conformidade com a normatização da aplicação do TAF da PMPR.

Palavras-chave: Teste físico, condicionamento físico, Teste de Cooper, flexão em barra fixa.

\section{INTRODUÇÃO}

O modo de vida da humanidade tem se modificado devido aos inúmeros avanços tecnológicos e científicos que surgem todos os dias. Essa evolução é de suma relevância, contudo, quando em excesso, tais avanços acarretam circunstâncias negativas que acabam prejudicando a qualidade de vida, conforme Neder (2001). Hoje em dia o ser humano não é tão ativo como foi no passado. A tecnologia é facilitadora de muitas ações diárias, permitindo, ao homem, um maior tempo de acomodação, entretanto, por outro lado, há uma acumulação de energia e estoque de gordura não eliminada, sendo algo prejudicial para o corpo (REPRESAS, 2000).

Os policiais militares (PMs) compõem um grupo de profissionais distintos dos demais, devido ao fato de enfrentarem, diariamente, situações inerentes à sua atividade profissional. A alta carga horária de trabalho destes, bem como o estresse encarado pela própria natureza laboral da profissão tendem a predispor esses cidadãos à 
preocupantes riscos relacionados à sua saúde (CALANZAS, 1996). Segundo Gonçalves (2006, p. 3):

Os níveis de saúde e bem-estar no trabalho podem levar a consequências danosas tanto para o indivíduo quanto para a empresa, e trabalhadores com baixo nível de saúde podem ser menos produtivos e apresentar menor capacidade de decisões, ficando mais predispostos ao absenteísmo.

Cabe destacar, considerando o disposto, que em razão do fato de a profissão militar ser desgastante e cansativa em demasia, os profissionais à ela relacionados, consequentemente, precisam buscar, de modo contínuo, pela melhora do seu condicionamento físico, isto é, para que possam desempenhar as tarefas exigidas diariamente é preciso que se tenha uma boa aptidão física, como apontam as reflexões de Zorec (2001). Para o Conselho do Presidente voltado à Aptidão Física e Esportes dos Estados Unidos, e, segundo Barbanti (1990, p. 11): a aptidão física é entendida como "a capacidade de executar tarefas diárias com vigor e vivacidade, sem fadiga excessiva e com ampla energia, para apreciar as ocupações das horas de lazer e para enfrentar emergências imprevistas".

Nesse contexto, cabe auferir, conforme a American College of Sports Medicine (1998), que as doenças compreendidas como de caráter crônico-degenerativo acarreta problemas como, por exemplo, a elevação dos níveis de colesterol sanguíneo; hipertensão; osteoartrite; acidente vascular cerebral; câncer em suas mais diversas tipologias; doenças coronarianas; depressão e ansiedade. A associação aponta, também, que os problemas sociais também, junto aos fatores físicos mencionados, dizem respeito à gordura corporal em demasia. Dessa maneira, a prática de atividade física é primordial para a preservação da saúde dos policiais militares e, consequentemente, implica numa melhora do condicionamento físico dos mesmos, contribuindo para o desempenho de suas atividades diárias (MACEDO et al, 2003). 


\section{OBJETIVOS}

\subsection{OBJETIVO GERAL}

- Avaliar a aptidão física dos policiais militares do 16을 BP e, por meio de uma revisão bibliográfica, compreender a importância de um adequado condicionamento físico para atividade profissional dos policiais militares.

\subsection{OBJETIVOS ESPECÍFICOS}

- Aplicar os testes de Cooper, Barra e Shuttle Run em policiais militares do $16^{\circ}$ BPM do Paraná;

- Comparar os resultados alcançados pelos policiais do 16으 BPM com outros estudos de aptidão física realizados com militares de outras regiões do país.

\section{REFERENCIAL TEÓRICO}

\subsection{APTIDÃO FÍSICA}

O fato de o indivíduo ser dotado de uma boa aptidão física é visto como algo de grande importância em nossa sociedade atualmente, pois isso significa que ele apresenta capacidade de desempenho e um estado de bem-estar (SILVA et al, 2009). O treinamento dessa aptidão a partir da atividade física e demais exercícios proporciona uma melhora das capacidades de desempenho corporal/físico. Sendo assim, é considerado um componente fundamental da aptidão total do ser humano, e, desse modo, aufere-se que os militares que possuem uma boa aptidão física podem impedir as afecções, bem como há a melhora da imagem da corporação junto à sociedade (ZOREC, 2001). Segundo Guedes (1996), em seu capítulo nas "Orientações Básicas sobre Atividades Físicas e Saúde para Profissionais das Áreas de Educação e Saúde", aptidão física é:

[...] um estado dinâmico de energia e vitalidade que permite a cada um não apenas a realização das tarefas do cotidiano, as ocupações ativas 
das horas de lazer e enfrentar emergências imprevistas sem fadiga excessiva, mas, também, evitar 0 aparecimento das funções hipocinéticas, enquanto funcionando no pico da capacidade intelectual e sentindo uma alegria de viver.

O referido autor também defende a ideia de que a aptidão física é a capacidade de atingir esforços físicos sem chegar ao cansaço em seu nível máximo. É, então, uma forma de se fomentar a sobrevivência do sujeito, garantindo, para tanto, condições orgânicas ideais ao meio a ele relacionado (GUEDES, 1996). Já para Hebbelinck (1984), um ser humano apto deve estar psicologicamente estável, ou seja, a tensão não deve impedir o seu bom desempenho. Possui, ainda, uma percepção ampla sobre o meio ao seu redor é consegue se ajustar facilmente a ele. Gallahue e Ozmun (2005), em suas reflexões, afirmam que aptidão física deve ser compreendida como uma condição positiva de bem-estar, e, devido à tal caráter, é propiciada quando a atividade física é regular, quando as características genéticas são favoráveis e em razão da adequação nutricional.

Portanto, se o indivíduo tiver uma boa aptidão física, consequentemente conseguirá realizar as atividades diárias com um bom desempenho, impedindo o surgimento da fadiga precoce. É importante ressaltar que o treinamento de aptidão física, por meio de atividades físicas apropriadas, proporciona benefícios à saúde do ser humano e ajuda a prevenir o aparecimento de doenças hipocinéticas (PATE, 1998). A aptidão física alcançada a partir da realização de atividades físicas regulares deve ser promovida durante todas as fases da vida do indivíduo, desde a infância até a velhice. Dessa maneira, será possível alcançar um bom desempenho físico/corporal nas atividades diárias, adiar o aparecimento da fadiga constante, evitar o surgimento de doenças e chegar a um bom estado de saúde, bem estar e qualidade de vida (MOREIRA et al, 2011). 


\section{METODOLOGIA}

\subsection{TIPOS DE ESTUDO}

Optamos por uma pesquisa transversal que consiste na observação da situação de saúde de uma população ou comunidade, baseando-se, para tanto, numa avaliação individual do estado de saúde de cada um dos membros participante (ROUQUAYROL et al, 2003). Parte-se do método quantitativo e descritivo para analisar os dados sobre a amostra escolhida, e, para tanto, serão confrontados com o referencial teórico a partir de tabelas.

\subsection{POPULAÇÃO E AMOSTRA}

Os sujeitos escolhidos para a realização desta pesquisa foram 23 policiais militares do sexo masculino integrantes do $16^{\circ} \mathrm{BPM}$, com sede no município de Guarapuava PR, com idade entre 29 e 52 anos, que possuíam tempo mínimo de 10 anos de serviço operacional e apresentaram atestado médico, estando aptos para realizar atividades físicas, com condições de saúde necessárias para realizar os testes propostos, que não estivessem fazendo uso de medicamentos, que não apresentassem lesões osteomusculares no período de avaliação e que estivessem aptos para serem promovidos dentro da corporação.

\subsection{COLETA DE DADOS E PROCEDIMENTOS}

Os dados dos policiais militares avaliados foram coletados durante a realização do TAF anual obrigatório realizado pela PMPR. Para avaliar o nível de aptidão física dos participantes da pesquisa, aplicou-se testes de flexão na barra fixa, corrida de 12 minutos (Cooper) em uma pista de atletismo de 400 metros, demarcada a cada 50 metros, flexão com o braço e Shuttle Run (corrida de ir e vir), nos mesmos moldes do Teste de Aptidão Física realizado pela Polícia Militar do Paraná (ESTADO DO PARANÁ, 2019). Para definir se o policial era considerado apto ou não nos testes aplicados foram usados como referência os critérios descritos no Quadro 1. São 
critérios utilizados para avaliar os níveis de aptidão física na Polícia Militar do Estado do Paraná, de acordo com a Portaria do Comando Geral № 076 (2016).

Quadro 1: Critérios de pontuação para avaliar se o policial militar é apto ou não durante o teste de aptidão física

\begin{tabular}{|c|c|c|c|c|c|c|c|c|c|c|c|c|c|c|c|}
\hline \multicolumn{5}{|c|}{ PROVAS } & \multicolumn{11}{|c|}{ PONTOS POR FAIXAS ETÁRIAS } \\
\hline $\begin{array}{c}\text { Shuttle } \\
\text { Run } \\
\text { (segundo } \\
\text { s) }\end{array}$ & 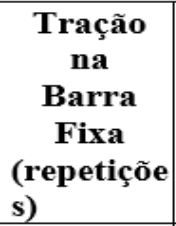 & $\begin{array}{l}\text { Apoio de } \\
\text { Braços } \\
\text { Sobre o } \\
\text { Solo } \\
\text { (repetiçõe } \\
\text { s) } \\
\end{array}$ & $\begin{array}{l}\text { Isometri } \\
\text { a na } \\
\text { Barra } \\
\text { Fixa } \\
\text { (segundo } \\
\text { s) } \\
\end{array}$ & $\begin{array}{l}\text { Corri } \\
\text { da } \\
12 \text { min } \\
\text { (metro } \\
\text { s) }\end{array}$ & $\begin{array}{c}\text { Até } \\
20\end{array}$ & $\begin{array}{c}21 \\
a \\
23\end{array}$ & $\begin{array}{c}24 \\
\mathbf{a} \\
26\end{array}$ & $\begin{array}{c}27 \\
\mathbf{a} \\
\mathbf{2 9}\end{array}$ & $\begin{array}{c}30 \\
\mathbf{a} \\
32\end{array}$ & \begin{tabular}{c|}
33 \\
$\mathbf{a}$ \\
35
\end{tabular} & $\begin{array}{c}36 \\
\mathbf{a} \\
38\end{array}$ & $\begin{array}{c}39 \\
\mathbf{a} \\
41\end{array}$ & $\begin{array}{c}42 \\
a \\
44\end{array}$ & $\begin{array}{c}45 \\
a \\
48\end{array}$ & $\begin{array}{l}\geq \\
49\end{array}$ \\
\hline Até 14,4 & & 04 & Até 1,0 & 1.250 & & & & & & & & & 01 & 02 & 03 \\
\hline Até 14,3 & & 06 & $>1,0$ a 2,0 & 1.300 & & & & & & & & & 02 & 03 & 05 \\
\hline Até 14,2 & & 08 & $>2,0$ a 3,0 & 1.350 & & & & & & & & 01 & 03 & 05 & 07 \\
\hline Até 14,1 & & 10 & $>3,0$ a 4,0 & 1.400 & & & & & & & & 02 & 04 & 06 & 08 \\
\hline Até 14,0 & & 12 & $>4,0$ a 5,0 & 1.450 & & & & & & & 01 & 03 & 05 & 07 & 09 \\
\hline Até 13,8 & & 13 & $>5,0$ a 7,0 & 1.500 & & & & & & & 02 & 04 & 06 & 08 & 10 \\
\hline Até 13,6 & & 14 & $>7,0$ a 9,0 & 1.550 & & & & & & 01 & 03 & 05 & 07 & 09 & 15 \\
\hline Até 13,4 & & 15 & $\begin{array}{c}>9,0 \mathrm{a} \\
10,0\end{array}$ & 1.600 & & & & & & 02 & 04 & 06 & 08 & 10 & 20 \\
\hline Até 13,3 & & 16 & $\begin{array}{l}>10,0 \text { a } \\
11,0\end{array}$ & 1.650 & 01 & & & & 01 & 03 & 05 & 07 & 09 & 15 & 25 \\
\hline Até 13,2 & & 17 & $>11,0 \mathrm{a}$ & 1.700 & 02 & & & & 02 & 04 & 06 & 08 & 10 & 20 & 30 \\
\hline
\end{tabular}

\begin{tabular}{|c|c|c|c|c|c|c|c|c|c|c|c|c|c|c|c|}
\hline & & & 12,0 & & & & & & & & & & & & \\
\hline Até 13,1 & & 18 & $\begin{array}{l}>12,0 \text { a } \\
13,0\end{array}$ & 1.750 & 03 & 01 & & 01 & 03 & 05 & 07 & 09 & 15 & 25 & 35 \\
\hline Até 13,0 & & 19 & $\begin{array}{l}>13,0 \text { a } \\
14,0\end{array}$ & 1.800 & 04 & 02 & & 02 & 04 & 06 & 08 & 10 & 20 & 30 & 40 \\
\hline Até 12,8 & & 20 & $\begin{array}{l}>14,0 \mathrm{a} \\
15,0\end{array}$ & 1.850 & 05 & 03 & 01 & 03 & 05 & 07 & 09 & 15 & 25 & 35 & 45 \\
\hline Até 12,6 & & 21 & $\begin{array}{l}>15,0 \mathrm{a} \\
16,0\end{array}$ & 1.900 & 06 & 04 & 02 & 04 & 06 & 08 & 10 & 20 & 30 & 40 & 50 \\
\hline Até 12,4 & 01 & 22 & $\begin{array}{l}>16,0 \mathrm{a} \\
17,0\end{array}$ & 1.950 & 07 & 05 & 03 & 05 & 07 & 09 & 15 & 25 & 35 & 45 & 55 \\
\hline Até 12,2 & 02 & 23 & $\begin{array}{l}>17,0 \text { a } \\
18,0\end{array}$ & 2.000 & 08 & 06 & 04 & 06 & 08 & 10 & 20 & 30 & 40 & 50 & 60 \\
\hline Até 12,0 & & 24 & $\begin{array}{l}>18,0 \text { a } \\
19,0\end{array}$ & 2.050 & 09 & 07 & 05 & 07 & 09 & 15 & 25 & 35 & 45 & 55 & 65 \\
\hline Até 11,9 & 03 & 25 & $\begin{array}{l}>19,0 \text { a } \\
20,0\end{array}$ & 2.100 & 10 & 08 & 06 & 08 & 10 & 20 & 30 & 40 & 50 & 60 & 70 \\
\hline Até 11,8 & & 26 & $\begin{array}{l}>20,0 \text { a } \\
21,0\end{array}$ & 2.150 & 15 & 09 & 07 & 09 & 15 & 25 & 35 & 45 & 55 & 65 & 75 \\
\hline Até 11,7 & 04 & 27 & $\begin{array}{l}>21,0 \text { a } \\
22,0\end{array}$ & 2.200 & 20 & 10 & 08 & 10 & 20 & 30 & 40 & 50 & 60 & 70 & 80 \\
\hline Até 11,6 & & 28 & $\begin{array}{l}>22,0 \text { a } \\
23,0\end{array}$ & 2.250 & 25 & 15 & 09 & 15 & 25 & 35 & 45 & 55 & 65 & 75 & 85 \\
\hline Até 11,5 & 05 & 29 & $\begin{array}{l}>23,0 \text { a } \\
25,0\end{array}$ & 2.300 & 30 & 20 & 10 & 20 & 30 & 40 & 50 & 60 & 70 & 80 & 90 \\
\hline Até 11,4 & & 30 & $\begin{array}{l}>25,0 \text { a } \\
27,0\end{array}$ & 2.350 & 35 & 25 & 15 & 25 & 35 & 45 & 55 & 65 & 75 & 85 & 95 \\
\hline Até 11,3 & 06 & 31 & $\begin{array}{l}>27,0 \text { a } \\
29,0\end{array}$ & 2.400 & 40 & 30 & 20 & 30 & 40 & 50 & 60 & 70 & 80 & 90 & \begin{tabular}{l|}
10 \\
0
\end{tabular} \\
\hline Até 11,2 & & 32 & $\begin{array}{l}>29,0 \text { a } \\
31,0\end{array}$ & 2.450 & 45 & 35 & 25 & 35 & 45 & 55 & 65 & 75 & 85 & 95 & \\
\hline Até 11,1 & 07 & 33 & $\begin{array}{l}>31,0 \text { a } \\
33,0\end{array}$ & 2.500 & 50 & 40 & 30 & 40 & 50 & 60 & 70 & 80 & 90 & \begin{tabular}{l|}
10 \\
0
\end{tabular} & \\
\hline
\end{tabular}

$\mathrm{RC}: 52807$

Disponível em: https://www.nucleodoconhecimento.com.br/educacao-fisica/policiais-militares 


\begin{tabular}{|c|c|c|c|c|c|c|c|c|c|c|c|c|c|c|}
\hline Até 11,0 & & 34 & $\begin{array}{l}>33,0 \mathrm{a} \\
35,0\end{array}$ & 2.550 & 55 & 45 & 35 & 45 & 55 & 65 & 75 & 85 & 95 & \\
\hline Até 10,9 & 08 & 35 & $\begin{array}{l}>35,0 \text { a } \\
37,0\end{array}$ & 2.600 & 60 & 50 & 40 & 50 & 60 & 70 & 80 & 90 & $\begin{array}{l}10 \\
0 \\
\end{array}$ & \\
\hline Até 10,8 & & 36 & $\begin{array}{l}>37,0 \text { a } \\
39,0\end{array}$ & 2.650 & 65 & 55 & 45 & 55 & 65 & 75 & 85 & 95 & & \\
\hline Até 10,7 & 09 & 37 & $\begin{array}{l}>39,0 \mathrm{a} \\
41,0\end{array}$ & 2.700 & 70 & 60 & 50 & 60 & 70 & 80 & 90 & $\begin{array}{l}10 \\
0\end{array}$ & & \\
\hline Até 10,6 & & 38 & $\begin{array}{l}>41,0 \text { a } \\
43,0\end{array}$ & 2.750 & 75 & 65 & 55 & 65 & 75 & 85 & 95 & & & \\
\hline Até 10,5 & 10 & 39 & $\begin{array}{l}>43,0 \mathrm{a} \\
45,0\end{array}$ & 2.800 & 80 & 70 & 60 & 70 & 80 & 90 & $\begin{array}{l}10 \\
0\end{array}$ & & & \\
\hline Até 10,4 & & & $\begin{array}{l}>45,0 \text { a } \\
47,0\end{array}$ & 2.850 & 85 & 75 & 65 & 75 & 85 & 95 & & & & \\
\hline Até 10,3 & 11 & & $\begin{array}{l}>47,0 \text { a } \\
49,0\end{array}$ & 2.900 & 90 & 80 & 70 & 80 & 90 & \begin{tabular}{l|l|}
10 \\
0 \\
\end{tabular} & & & & \\
\hline Até 10,2 & & & $\begin{array}{l}>49,0 \text { a } \\
51,0\end{array}$ & 2.950 & 95 & 85 & 75 & 85 & 95 & & & & & \\
\hline Até 10,1 & 12 & & $\begin{array}{l}>51,0 \mathrm{a} \\
53,0\end{array}$ & 3.000 & $\begin{array}{l}10 \\
0\end{array}$ & 90 & 80 & 90 & \begin{tabular}{l|l}
10 \\
0
\end{tabular} & & & & & \\
\hline
\end{tabular}

\begin{tabular}{|c|c|c|c|c|c|c|c|c|c|c|c|c|c|c|c|}
\hline Até 10,0 & 13 & $\begin{array}{l}>53,0 \mathrm{a} \\
55,0\end{array}$ & 3.050 & & 95 & 85 & 95 & & & & & & & \\
\hline Até 9,8 & 14 & & $\begin{array}{l}>55,0 \mathrm{a} \\
57,0\end{array}$ & 3.100 & & $\begin{array}{l}10 \\
0\end{array}$ & 90 & $\begin{array}{l}10 \\
0\end{array}$ & & & & & & & \\
\hline Até 9,4 & 15 & & $\begin{array}{l}>57,0 \mathrm{a} \\
59,0\end{array}$ & 3.150 & & & 95 & & & & & & & & \\
\hline Até 9,2 & 16 & & $>59,0$ & 3.200 & & $\begin{array}{l}10 \\
0\end{array}$ & & & & & & & & \\
\hline
\end{tabular}

\section{Critérios para Aprovação no TAF}

1. $O$ avaliado deverá atingir o mínimo de pontos de 2 . $O$ avaliado não poderá deixar de acordo com a sua faixa etária, somadas as três marcar pontos em nenhuma das provas. pontuações, da seguinte forma:

- Até 35 anos: $\mathbf{1 5 0}$ pontos.

- De 36 a 45 anos: $\mathbf{1 4 0}$ pontos.

- Acima de 45 anos: $\mathbf{1 3 0}$ pontos. - Tração na barra fixa e isometria na barra fixa com pegada em pronaç̃o. - Optativa tração na barra fixa ou Isometria e, a partir dos 36 anos, optativo apoio de braços sobre o solo.

3. Na prova de corrida 12 minutos, para fins de pontuação, a partir de 10 pontos, cada 10 metros percorridos equivalerão a 01 ponto na tabela.

Fonte: Portaria do Comando-Geral № 076/2016 (Teste De Aptidão Física - Masculino)

\subsubsection{FLEXÃO NA BARRA FIXA}

Segundo Silva (1999), a Flexão na Barra Fixa tem em vista desenvolver a força muscular dos membros superiores. No contexto militar, essa atividade fomenta melhores ações de combate, pois proporciona, ao militar, mais autonomia para

Disponível em: https://www.nucleodoconhecimento.com.br/educacao-fisica/policiais-militares 
conseguir suportar e erguer o peso do próprio corpo, o que é de extrema importância em inúmeras situações vivenciadas por esses profissionais. Ao executar esse exercício, o policial militar fica pendurado na barra com os braços estendidos e afastados na largura dos ombros, segurando a barra com as mãos em pronação, ou seja, com a palma da mão voltada para baixo. Então, o indivíduo fará várias flexões de braço na barra fixa, segurando a barra durante todo o tempo do exercício (BRASIL, 2002).

\subsubsection{FLEXÃO COM O USO DO BRAÇO}

O exercício de flexão de braço é usado para avaliar o desempenho muscular hipertrófico dos músculos peitorais e da porção clavicular do deltóide, e, também, pode ser utilizado para obter um aumento da força dos braços (BORSTAD et al, 2009). Segundo o mesmo autor, a flexão de braço ainda é utilizada como forma de melhorar o desempenho dos músculos secundários dos ombros, dos braços e do tronco e, ainda, para aumentar a resistência muscular do praticante.

O Teste teve 1 minuto de duração. Para que a atividade transcorra de forma adequada o profissional deve ficar em decúbito ventral, isto é, com as mãos apoiadas no chão, sendo a distância ideal de 10 a $20 \mathrm{~cm}$ a partir da linha dos ombros. Os dedos, por sua vez, voltam-se para a frente. Sobre a posição ideal das mãos sobre o chão, é recomendado que não seja acima da linha dos ombros. Para começar o movimento em questão é preciso que o rosto esteja alinhado adequadamente com o tronco e as pernas (MAYHEW, 1991; QUEIROGA, 2005).

\subsubsection{TESTE DE COOPER}

O teste de Cooper, mais conhecido como corrida de 12 minutos, pertence à categoria dos testes submaximais para estimar o consumo máximo de oxigênio $\mathrm{VO}_{2}$ max. É muito utilizado pela facilidade de administração, baixo custo e a possibilidade de várias pessoas serem avaliadas ao mesmo tempo (ACSM, 2003). Basicamente, o profissional militar deverá percorrer a maior distância possível no tempo 
de 12 minutos. É permitido andar, mas é melhor evitar e o deslocamento deverá obedecer a um ritmo/cadência.

\subsubsection{TESTE SHUTTLE RUN}

Esse teste consiste em avaliar o tempo gasto para realização de um percurso prédefinido em movimento de ida e volta (AAHPER, 1976). Para iniciar o teste, é preciso demarcar duas linhas com 1 metro de largura. As duas são demarcadas paralelamente, numa distância de 9,14m. Atrás de uma das linhas, deve-se colocar dois objetos (blocos), sendo que estes devem ter um afastamento de $10 \mathrm{~cm}$ das linhas e $30 \mathrm{~cm}$ entre eles. Então, o indivíduo deve se posicionar em pé, atrás da linha de saída do teste, com as pernas em afastamento ântero-posterior, com o pé mais próximo possível da linha de saída.

Assim sendo, dando continuidade ao exercício, o profissional militar submetido ao teste, ao ouvir o comando do avaliador, e, também, com o acionamento do cronômetro, o avaliado em ação simultânea deve correr em máxima velocidade possível até os blocos, sempre passando um dos pés para fora da linha, pegar um deles e retornar ao ponto de onde partiu, deixando o mesmo atrás da linha de partida, sendo necessário repetir o mesmo processo para pegar o segundo bloco. $O$ trajeto em questão é cronometrado. Encerra-se quando o avaliado ultrapassa a referida linha por uma segunda vez (AAHPER, 1976).

\section{RESULTADOS E DISCUSSÃO}

Os dados sobre o teste encontram-se dispostos na Tabela 1. Apontam a pontuação de cada policial e essa indica, portanto, se os militares estão ou não aptos para desempenhar suas atividades diárias. Conforme o Quadro 1, o avaliado deve atingir o mínimo de pontos de acordo com sua faixa etária. Cada prova tem o valor máximo de 100 pontos, podendo o indivíduo totalizar 300 pontos. O avaliado não pode zerar em nenhuma das provas e para ser considerado apto, o militar do sexo masculino deve atingir, no mínimo: 
- Até 35 anos: 150 pontos;

- De 36 a 45 anos: 140 pontos;

- Acima de 45 anos: 130 pontos.

Tabela 1: Performance individual dos militares com a aplicação do Teste de Aptidão Física (TAF) no contexto paranaense

\begin{tabular}{|c|c|c|c|c|c|c|c|}
\hline \multirow{2}{*}{$\begin{array}{l}\text { Policia } \\
\text { is }\end{array}$} & \multirow{2}{*}{$\begin{array}{l}\text { Idad } \\
\text { e } \\
\text { (ano } \\
\text { s) }\end{array}$} & \multicolumn{4}{|c|}{ Testes aplicados } & \multirow{2}{*}{$\begin{array}{l}\text { Pontuaç } \\
\text { ão }\end{array}$} & \multirow{2}{*}{$\begin{array}{l}\text { Resulta } \\
\text { do }\end{array}$} \\
\hline & & $\begin{array}{l}\text { Shuttle } \\
\text { run } \\
\text { (segundo } \\
\text { s) }\end{array}$ & $\begin{array}{l}\text { Flexão de } \\
\text { braço } \\
\text { (repetiçõ } \\
\text { es) }\end{array}$ & $\begin{array}{l}\text { Barra fixa } \\
\text { (repetiçõ } \\
\text { es) }\end{array}$ & $\begin{array}{l}\text { Coope } \\
r \\
\text { (metro } \\
\text { s) }\end{array}$ & & \\
\hline 1 & 52 & 10,7 & $x$ & 9 & 2.840 & 300 & Apto \\
\hline 2 & 50 & 10,7 & 32 & $x$ & 2.155 & 275 & Apto \\
\hline 3 & 46 & 10,7 & $\mathrm{X}$ & 8 & 2.200 & 270 & Apto \\
\hline 4 & 29 & 10 & $\mathrm{X}$ & 16 & 2.760 & 260 & Apto \\
\hline 5 & 45 & 10,9 & $x$ & 11 & 2.540 & 300 & Apto \\
\hline 6 & 36 & 9,7 & $x$ & 13 & 2.710 & 290 & Apto \\
\hline 7 & 46 & 9,9 & 40 & $\mathrm{X}$ & 1.980 & 250 & Apto \\
\hline 8 & 38 & 10,4 & $\mathrm{x}$ & 5 & 2.250 & 195 & Apto \\
\hline 9 & 37 & 9,9 & 35 & $x$ & 2.490 & 250 & Apto \\
\hline 10 & 42 & 10,6 & $x$ & 9 & 2.540 & 295 & Apto \\
\hline 11 & 39 & 11 & 36 & $\mathrm{x}$ & 2.150 & 225 & Apto \\
\hline 12 & 35 & 10 & $x$ & 11 & 2.530 & 265 & Apto \\
\hline 13 & 44 & 9,7 & $X$ & 15 & 2.600 & 300 & Apto \\
\hline 14 & 40 & 11 & 18 & $x$ & 2.015 & 124 & Inapto \\
\hline 15 & 38 & 11,5 & 21 & $x$ & 2.240 & 105 & Inapto \\
\hline 16 & 35 & 9,6 & $X$ & 16 & 2.900 & 300 & Apto \\
\hline 17 & 39 & 11,5 & $X$ & 3 & 1.760 & 109 & Inapto \\
\hline 18 & 39 & 11,2 & 35 & $x$ & 2.010 & 195 & Apto \\
\hline 19 & 35 & 9,4 & $x$ & 18 & 3.210 & 300 & Apto \\
\hline
\end{tabular}




\begin{tabular}{|l|l|l|l|l|l|l|l|}
\hline $\mathbf{2 0}$ & 50 & 9,8 & $\mathrm{X}$ & 9 & 2.500 & 300 & Apto \\
\hline $\mathbf{2 1}$ & 41 & 10,6 & 30 & $\mathrm{X}$ & 2.240 & 220 & Apto \\
\hline $\mathbf{2 2}$ & 38 & 11,1 & 18 & $\mathrm{X}$ & 2.010 & 127 & Inapto \\
\hline $\mathbf{2 3}$ & 39 & 11,2 & 20 & $\mathrm{X}$ & 2.100 & 130 & Inapto \\
\hline
\end{tabular}

Legenda: $\mathrm{x}$ - sem resultado.

Fonte: Elaborado pelo autor (2020)

Avaliando os resultados obtidos pelos policiais, de acordo com Quadro 1, é possível identificar que $21,7 \%$ dos militares não conseguiram chegar à pontuação ideal à sua idade quando submetidos ao teste do TAF. Constatou-se, também, que os avaliados inaptos têm idade entre 38 a 40 anos e os aptos com a pontuação máxima encontramse na faixa etária acima dos 35 anos. A Tabela 2, por conseguinte, registra os dados voltados às médias obtidas pelos militares no que tange os testes de Shuttle Run, flexão de braço, barra fixa e Cooper. Analisando de acordo com os critérios da Portaria do Comando-Geral № 076 (2016), apresentados no Quadro 1, é possível identificar que no teste de agilidade Shuttle Run a média foi de 10,48 segundos, assim como a média de idade foi de 40,56 anos. Considerando tais variáveis, cabe auferir que os policiais avaliados obtiveram um resultado médio superior ao tempo necessário para obter a pontuação máxima, que seria de 10,7 segundos para 100 pontos.

No teste de flexão de braço, a média dos policiais avaliados foi de 28,5 repetições, equivalendo a 55 pontos. Com relação à barra fixa, o resultado médio da população estudada foi de 11 repetições, ultrapassando as 9 necessárias para obter a pontuação máxima para a idade. Por último, analisando o Teste de Cooper, a média foi de 2.368 metros, com pontuação correspondente de 65 pontos. Com base nas médias obtidas nos testes, os policiais avaliados alcançaram um total de 220 pontos, caso analisemos os resultados de todos os testes aqui referenciados. Se considerarmos os testes de Shutle Run, Cooper e barra fixa, os policiais obteriam 265 pontos, tendo em vista que o candidato tem direito de optar a partir dos 36 anos de idade por realizar a flexão de braço ou repetições em barra fixa. Independente da escolha dos testes (flexão de braço ou repetições em barra fixa), em ambas as situações a média obtida pelo grupo 
de policiais avaliados superaria a pontuação mínima, que deve ser de 140 pontos para a referente média de idade.

Tabela 2: Avaliação da performance dos militares submetidos ao Teste de Aptidão Física (TAF) aplicado pela Polícia Militar do Estado do Paraná (PMPR)

\begin{tabular}{|l|l|l|l|l|}
\hline Variáveis (testes) & Média & $\begin{array}{l}\text { Desvio } \\
\text { padrão }\end{array}$ & Mínimo & Máximo \\
\hline Idade (anos) & 40,56 & 5,6 & 29 & 52 \\
\hline $\begin{array}{l}\text { Shuttle run (segundos) } \\
\text { Flexão de braço } \\
\text { (repetições) }\end{array}$ & 10,48 & 0,64 & 9,4 & 11,5 \\
\hline $\begin{array}{l}\text { Repetições em barra fixa } \\
\text { Cooper (metros) }\end{array}$ & 11 & 8,4 & 18 & 40 \\
\hline
\end{tabular}

Fonte: Elaborada pelo autor (2020)

Matos et al (2010) realizaram um estudo com 31 policiais, designados aleatoriamente na faixa etária de 30 a 39 anos, no 38 Batalhão da Polícia Militar do Estado do Rio de Janeiro. A pesquisa concluiu que o batalhão em questão possuía níveis positivos em relação à força e condicionamento aeróbio, uma vez que as médias pelos autores obtidas apontaram que o mínimo exigido havia sido atingido, em consonância com as indicações do TAF. Relacionando os dois estudos, apesar de Matos et al (2010) estabelecerem um limite de idade até 39 anos e o presente estudo a média de idade ser de 40,56 anos, a média obtida com a aplicação do Teste de Cooper no trabalho de Matos et al (2010) foi de $2.580 \mathrm{~m}$, contra $2.368 \mathrm{~m}$ do presente estudo. O percurso mínimo estabelecido pelo Testes de Cooper, segundo Matos et al (2010) foi de $2.100 \mathrm{~m}$, contra $1.760 \mathrm{~m}$ do presente estudo. Já com relação ao percurso máximo obtido no presente estudo foi de $3.210 \mathrm{~m}$, superior aos $3.100 \mathrm{~m}$ obtidos por Matos et al (2010). No teste de tração da Barra Fixa, observou-se valores superiores no presente estudo, tanto na média, quanto em relação mínimo necessário indicado pelo TAF, respeitando as indicações por idade. A média das trações em barra fixa do presente estudo foi de 11, com mínima de 3 e máxima de 18 repetições, enquanto no trabalho 
de Matos et al (2010) os militares avaliados obtiveram média de 6,5, mínima de 2 e máxima de 8 repetições. De forma geral, a comparação com o estudo de Matos et al (2010) demonstrou que os policiais do presente estudo estavam com um bom condicionamento físico, tendo que vista que obtiveram superioridade em alguns testes, mesmo se tratando de uma população com idade um pouco superior.

\section{CONSIDERAÇÕES FINAIS}

Com base nos dados, foi possível perceber que os policiais do 16 Batalhão de Polícia Militar de Guarapuava - PR que possuem mais de 10 anos de serviço operacional apresentaram uma boa condição física. Resultado esse que é de suma importância, pois um bom condicionamento acarreta um desempenho melhor pelos profissionais dessa área. O preparo físico adequado é indispensável aos policiais militares, já que é necessário que corpo e mente estejam em perfeito estado para a realização das atividades de sua responsabilidade. Por outro lado, o incentivo à prática de atividades físicas no 16ํㅡㄹ BPM aponta ótimos resultados para a polícia militar paranaense, uma vez que detectou-se uma melhora da qualidade de vida dos policiais, o que faz com que possam atender com excelência a sociedade da região abrangente pelo $16^{\circ}$ BPM.

\section{REFERÊNCIAS}

ALLIANCE FOR HEALTH, PHYSICAL EDUCATION, AND RECREATION. AAHPER. Youth Fitness Test Manual. Washington, DC: American Alliance for Health, Physical Education and Recreation, 1976.

American College Of Sports Medicine. Diretrizes do ACSM para os testes de esforço e sua prescrição. 6ª ed. Rio de Janeiro: Guanabara Koogan, 2003.

American Alliance for Health, physical education, recreation and dance. Physical best. Reston: Aahperd, 1988. American College of Sports Medicine. Manual para teste de esforço e prescrição de exercício. 4ª ed. Rio de Janeiro: Revinter, 1996.

BARBANTI, V. J. Aptidão física: um convite à saúde. São Paulo: Manole, 1990. 
BORSTAD, J. D.; SZUCS, K.; NAVALGUND, A. Scapula kinematic alterations following a modified push-up plus task. Med Biol Eng Comp., v. 47, n. 5, p. 487-495, mai. 2009.

BORSTAD, J. D.; SZUCS, K.; NAVALGUND, A. Scapula kinematic alterations following a modified push-up plus task. Human movement science, v. 28, n. 6 , p. 738-751, 2009.

BRASIL. Estado- Maior do Exército. C 20-20 Manual de Treinamento Físico Militar. Brasília: EGGCF, 2002.

CALAZANS, M. E. de. Missão prevenir e proteger: condições de vida, trabalho e saúde dos policiais militares do Rio de Janeiro. Cadernos de Saúde Pública, v. 26, n. 1, p. 206-211, jan. 2010.

COOPER, K. H. A means of assessing maximal oxygen intake: correlation between field and treadmill testing. Jama, v. 203, n. 3, p. 201-204, 1968.

DESHAIES, B. Metodologia da investigação em ciências humanas. Lisboa: Instituto Piaget, 1992.

ESTADO DO PARANÁ. Polícia Militar. Edital de abertura n 001/2019. Concurso ao Curso de Especialização em Cinotecnia Policial Militar - CCPM - Categoria Praças - Turma 2019. Academia de Policial Militar do Guatupê. 21 de out. de 2019.

GALLAHUE, D. L.; OZMUN, J. C. Compreendendo o Desenvolvimento Motor: bebês, crianças, adolescentes e adultos. 3를 ed. São Paulo: Phorte, 2005.

GONÇALVES, L. G. de O. Aptidão Física Relacionada à Saúde de Policiais Militares do Município de Porto Velho-RO. 2006. 88 f. Tese (Doutorado em Ciências da Saúde) - Universidade de Brasília, Brasília, 2006.

GUEDES, D. P. Atividade física, aptidão física e saúde. In: CARVALHO, T.; GUEDES, D. P.; SILVA, J. G. (orgs.). Orientações Básicas sobre Atividade Física e Saúde 
para Profissionais das Áreas de Educação e Saúde. Brasília: Ministério da Saúde e Ministério da Educação e do Desporto, 1996.

HEBBELINCK, M. The concept of health-related to physical fitness. International Journal of Physical Education, v. 21, n. I, p. 9- 18, 1984.

KNECHTEL, M. R. Metodologia da pesquisa em educação: uma abordagem teórico-prática dialogada. Curitiba: Intersaberes, 2014.

MACEDO, C. de. S. G. et al. Benefícios do exercício físico para a qualidade de vida. Revista Brasileira de Atividade Física \& Saúde, v. 8, n. 2, p. 19-27, 2003.

MAYHEW, J. L. et al. Push-ups as a measure of upper body strength. The Journal of Strength \& Conditioning Research, v. 5, n. 1, p. 16-21, 1991.

MATOS, D. G. de. et al. Perfil evolutivo do condicionamento aeróbio e da força em policiais militares. Revista de Atenção à Saúde, v. 8, n. 25, p. 14-22, 2010.

MOREIRA, O. C. et al. Associação entre risco cardiovascular e hipertensão arterial em professores universitários. Revista Brasileira de Educação Física e Esporte, v. 25, n. 3, p. 397-406, 2011.

NEDER, C. P. As influencias das novas tecnologias de comunicação social na formação política. In: Biblioteca Online de Ciências da Comunicação, São Paulo, 2001.

OLHER, R. R. V. Isometria submáxima envolvendo grandes grupos musculares induz hipotensão pós-exercício e melhora o estado redox em adultos hipertensos estágio 1. 2019. 124f. Tese (Doutorado em Educação Física) Universidade Católica de Brasília, Brasília, 2019.

. Portaria do Comando Geral № 076/2016. Curitiba, 22 de janeiro de 2016.

PATE, R. R. The evolving definition of physical fitness. Quest, v. 40, n. 3, p. 174-179, 1988. 
QUEIROGA, M. Testes e medidas para avaliação da aptidão física relacionada à saúde em adultos. Rio de Janeiro: Guanabara Koogan, 2005.

REPRESAS, J. P. As 7 Biorotas para a saúde, o Bem-Estar e a Longevidade. Rio de Janeiro: Record, 2000.

ROUQUAYROL, M. Z.; FILHO, N. A. Epidemiologia \& Saúde. Rio de Janeiro: Guanabara Koogan, 2003.

SILVA, E. B. Efeitos da Freqüência de Treinamento, Ritmo e Pegada na Puxada na Barra Sobre a Força Muscular e Creatina Quinase em Conscritos do Exército Brasileiro. 1999. 139f. Dissertação (Mestrado em Educação Física) - Universidade Gama Filho, Rio de Janeiro, 1999.

SILVA, D. A. S.; PETROSKI; E. L.; REIS, R. S. Barreiras e facilitadores de atividades físicas em frequentadores de parques públicos. Motriz, v.15, n. 2, p. 219-227, abr./jun. 2009.

ZOREC, B. Anthropometric characteristics in police officers. Journal of Criminal Justice and Security, v. 1, p. 26-35, 2001.

Enviado: Maio, 2020.

Aprovado: Junho, 2020. 